\title{
Licensing E-Books
}

\section{Emilie Algenio \& Alexia Thompson-Young}

To cite this article: Emilie Algenio \& Alexia Thompson-Young (2005) Licensing E-Books, Journal of Library Administration, 42:3-4, 113-128, DOI: 10.1300/J111v42n03 08

To link to this article: http://dx.doi.org/10.1300/J111v42n03_08

曲 Published online: 12 Oct 2008.

Submit your article to this journal $\pi$

Џ Article views: 248

Q View related articles $\widetilde{ }$

47 Citing articles: 6 View citing articles 진 


\title{
Licensing E-Books: The Good, the Bad, and the Ugly
}

\author{
Emilie Algenio \\ Alexia Thompson-Young
}

\begin{abstract}
SUMMARY. As e-books settle into the academic market, the relationship between publishers, vendors, and libraries grows more complex. This article highlights how licenses, which govern this business affair, are no exception. From aggregators to individual publishers, from large STM companies to small societies, e-book enterprises must acknowledge library values in order to remain economically viable. For the benefit of all parties involved, new and better ways of balancing the profit-driven goal of selling e-books and the educational benefit of lending e-books need to be negotiated. In an environment where communication is encouraged, flexible licenses and subscription models can balance these issues. [Article copies available for a fee from The Haworth Document Delivery Service: 1-800-HAWORTH. E-mail address: $<$ docdelivery@haworthpress.com> Website: <http://www.HaworthPress.com>]
\end{abstract}

Emilie Algenio is Assistant Licensing Coordinator (E-mail: algenio@mail.utexas. edu); and Alexia Thompson-Young is Licensing Coordinator (E-mail: atyoung@mail. utexas.edu), both at Digital Library Services Division, The General Libraries, University of Texas at Austin, First Floor Dock, Austin, TX 78713-8916.

The authors wish to acknowledge Dennis Dillon's expertise and exemplary e-book examinations.

(C) 2003 by Emilie Algenio and Alexia Thompson-Young. Reprinted with permission.

[Haworth co-indexing entry note]: "Licensing E-Books: The Good, the Bad, and the Ugly." Algenio, Emilie, and Alexia Thompson-Young. Co-published simultaneously in Journal of Library Administration (The Haworth Information Press, an imprint of The Haworth Press, Inc.) Vol. 42, No. 3/4, 2005, pp. 113-128; and: Licensing in Libraries: Practical and Ethical Aspects (ed: Karen Rupp-Serrano) The Haworth Information Press, an imprint of The Haworth Press, Inc., 2005, pp. 113-128. Single or multiple copies of this article are available for a fee from The Haworth Document Delivery Service [1-800-HAWORTH, 9:00 a.m. 5:00 p.m. (EST). E-mail address: docdelivery@ haworthpress.com].

http://www.haworthpress.com/web/JLA

Digital Object Identifier: 10.1300/J111v42n03_08 
KEYWORDS. E-books, electronic books, licensing, subscription models, digital content standards

An ever-increasing number of e-book offers, as e-mail announcements, web page advertisements, and even brightly colored postcards, are making their way from publishers to librarians. "Highly authoritative," "exceptionally usable," and "easily accessible" are among the descriptions listed in these offers. Underneath these pretty features, items that both publishers and librarians can agree on, are the e-book's business model and license, points where publishers and librarians are likely to disagree. Some may view e-book business models and corresponding licenses as ugly realities, but through earnest discussion bad models and licenses can be worked with.

The meaning of the term e-book can range from electronic copies of a book's printed form, to marked up text and figures that enhance the content of an e-book, to electronic content that offers online services beyond those of an individual book. Many e-book articles have investigated e-book formats, e-book reading devices and the general public's reading of popular e-books, such as author Stephen King's experiment in 2000. However, this article will focus on the e-book business models with online web access for academic libraries. Examining e-book publishing merits, such as the digitization cost, platform development, archiving mechanisms, marketing and pricing considerations, and internal content rights management, as well as external customer account management is highly complex. E-books are still in their infancy, and many aspects of the business have yet to become standard practices. Considering this, the instability of the content and medium, and the continuum of time, the authors are analyzing only a segment of the present to better predict the future. Examining library merits, such as licensing intellectual property rights, archival access, technological choices and maintenance, budget considerations, administrative reports, and accessibility issues is also highly complex. In practice, when it comes down to the details, no two e-book business models will be evaluated and subscribed to in the same way by any library. Therefore, this article will be generalizing e-book and library values for the sake of discussion.

Publishers want to sell books to customers and libraries want to lend books to users. E-books challenge both of these goals, since one e-book could be accessed by multiple library users at a time or could be protected by software that requires payment per view. Early e-book business models sought to avoid these revenue issues by digitizing older 
content that no longer had a substantial market share, such as the Early English Books Online (EEBO) collection. This collection has close to 100,000 online versions of books and other printed materials published in the English language from 1475 through 1700, and in many instances duplicates the print titles already held by academic libraries. The online benefit of greater accessibility to users with a web browser coupled with the timing of when EEBO was first offered for subscription, encouraged many libraries to purchase this content. As Dennis Dillon wrote in 2001, "After positive experiences with Web-based e-journals, full-text aggregators, and indexing and abstracting services, e-books were the obvious next step in our attempts to bring a full line-up of Web-based basic library resources to our clientele." 1 Now in the fall of 2003, libraries are dealing with shrinking budgets and are not as ready to purchase the same content in multiple formats. In this article we will review some current e-book proposals, recognize divergent e-book and library values, and suggest what good e-book business models and licenses the future may include.

\section{E-BOOK MERITS IN LIBRARY MARKET}

The e-book market is highly complex. Gone are the expectations that an e-book is just a book in electronic format that will be cheap to produce. This electronic format is being influenced by a number of factors such as the author's ability to enhance the content, the rethinking of the publishing supply chain, and the use of the e-book format with reading devices. Two very influential factors on the e-book market are the music industry's reaction to shareware, and the slightly more mature e-journal market. Like popular songs shared by Internet users, publishers are sensitive to the fact that e-books could be disseminated electronically to users without payment, unless e-books are protected with rights management software. This means that publishers must spend money upfront for computer programming and hardware, or pay for these services from an aggregator or other third party. At this point, an aggregator may successfully license a publisher's e-book content into an exclusive business deal, ensuring that libraries must gain access to the aggregator's e-book platform to access the desired content. The favored O'Reilly "nutshell" technology books are a good example of this. At one time, O'Reilly e-books were offered through one online platform that licensed access to academic libraries, but have since made their content available through other platforms. 
E-book business models will continue to evolve, but there are some broad categories that can be described. The more common business models include one e-book/one user, fees for simultaneous users, free with print purchases, and annual fees based on a library or institution's characteristics. These models can be tailored to fit any one library, or multi-library consortia, and generally are.

The one e-book/one user model is unofficially referred to as the netLibrary model, since netLibrary was one of the first aggregators to employ it. The netLibrary model allows a subscribing library to purchase an e-book close to the print price plus any quantity discounts, presents two options for a fee to cover netLibrary's online platform service, includes MARC records, and permits only one patron at a time to view or check out an e-book. This model resembles how print books are purchased with one-time fees, and how only one patron at a time can check a print book out. A crucial component of the model is that netLibrary's platform ensures that only one user at a time can view an e-book, and has built in safeguards to keep the e-book from being systematically disseminated to non-authorized users. This same platform provides statistics to libraries so they can see how their e-book titles are being used. This type of model, one e-book available to one user, is appreciated by publishers that are concerned that one e-book available to an unlimited number of users would decrease their sales. However, many libraries have grown to expect unlimited users with their electronic resources and consider models that are priced per user as behind the times. As a variation on the netLibrary model, Ebooks.com permits multiple users to simultaneously view one e-book.

Certain e-book genres-dictionaries, encyclopedias, directories-may also be freely accessed online by libraries that buy the print versions, hence the free with print purchase model. Since the current usefulness of these traditional print reference resources has a limited shelf life, online access to updated content is desirable. However, libraries usually will not be gaining long term access to the online content, nor will they have archival rights to the online version, but since the print version is already in their collection this may not be of consequence.

Specific genres lend themselves well to the e-book format, "bibliographies, abstracting and index guides, citation indexes, dictionaries, encyclopedias, directories, product catalogs, maintenance manuals . . . [have] succeeded because [they are] not literal translations of their predecessor print products." 2 These genres benefit from frequent content updates, something that is more easily done with e-books than with print books. Since these e-books are updated, online publishers use the annual 
fee model for these evolving monographs. These annual fees are usually based on institutional characteristics such as FTE or degrees granted, library characteristics such as Carnegie classifications, and/or a multiple library consortial discount. Libraries recognize the benefits of up-to-date content and have been willing to pay annual fees, especially if the fees are inexpensive. However, an inexpensive designation is a subjective concept, unique to each library.

Recently, many science, technology, and medical (STM) publishers have come out with their own e-book offers marketed directly to libraries instead of making their content obtainable through an e-book aggregator. These e-books may be considered to be reference materials, but they will generally contain more research content than the reference materials cited above. Most of these publishers are using e-book models that resemble their e-journal offers in that annual subscription fees are required. One of the reasons cited for an annual fee is that unlike their print predecessors, these electronic editions are updated online regularly, instantly available to users. Publishers will certainly view these e-books as more weighty in content than a mere index and will set the fees accordingly. Many libraries are not looking to add another annual fee to their subscription budgets, yet they might be willing to buy this research content and forgo the updates in favor of a one-time purchase. There is anecdotal evidence that some publishers are willing to offer this one-time purchase option for e-books which are normally advertised as annual subscriptions.

Finding new ways to provide access to e-books with a sustainable revenue is a challenge publishers and aggregators are accepting. A unique e-book model from Ebrary requires a free plug-in, and when once installed users may read e-books from more than 100 publishers online at no cost. Printing and downloading of content will require users to purchase the e-book, or these activities will be covered under prepaid library fees to Ebrary. Another upcoming experimental model from eBooks Corporation, announced at the Fall 2003 International Coalition of Library Consortia (ICOLC) meeting, will support "non-linear lending." E-books will be accessible to a subscribing library for a fixed number of days per year, and these days can be used concurrently depending on user demand. Experimental business models are needed to find new and perhaps better ways to balance the publisher's goal of selling books and the library's goal of lending them.

While a standard business model and license for e-books would be nice, such as the taken for granted standard of buying and using print monographs, the truth is that this utopia would be impossible. As new 
technologies develop, e-books will continue to evolve along with their business models and licenses. Publishers and librarians are well aware that licenses reflect more than the business model agreed to. Many states have licensing language that by law state-supported institutions must include in their contracts, and there are always institution and library specific language that should be included as well. The publisher also has specific language that will need to be addressed in their contracts. The licensing process is quite demanding, since all parties want to make sure that the license manifests the best e-book model possible. Noted by Ian Jacobs, with Palgrave Macmillan, in the context of licenses between publishers, "One might think that once the first one or two contracts have been negotiated then the third and fourth would take much less time. Unfortunately, this turns out not to be the case." $3 \mathrm{Li}$ censes will probably never be completely standardized for either publishers or libraries.

\section{LIBRARY MERITS IN LIBRARY MARKET}

Librarians have gained experience with subscribing to e-journals and certain subscription functionalities should now be expected for e-books. Bibliographers use statistics for their collection development efforts, and vendors oblige. Knowing the numbers is critical in gauging the utility of online resources, regardless of whether the vendor conforms to ICOLC's or the Counting Online Usage of NeTworked Electronic Resources' (COUNTER) guidelines. The time-honored Association of Research Libraries' statistics currently include guidelines on how to count e-books within the larger context of the collection <http://www. arl.org/stats/arlstat/arlstatqa.html>.

Recently, a few new offerings of e-books from publishers have been using the subscription model. Unlike buying a book, these models are built upon yearly fees like a journal subscription. A steady revenue stream for publishers is desirable, but libraries have to make hard choices about their online subscriptions. Many a subscription budget is being consumed with e-journal package fees, and when a library has to make a choice between an established, non-cancelable by license, peer reviewed e-journal and an e-book that also collects updated, edited articles from authors with an annual license fee, the library will most likely choose the e-journal.

As a business customer, libraries tend to purchase a single title, and a single title covering infinite subjects, as opposed to buying one title in 
bulk, and within a select subject range. As a whole, libraries' purchasing power has not reached a critical mass, at least not in the eyes of e-book publishers and not for the current output of e-book titles. For this reason, publishers have the advantage to push certain prices and licensing terms. Within the current legal landscape for libraries, e-books are governed by licenses, and are protected federally by the Digital Millennium Copyright Act (DMCA) and literally by digital rights management systems (DRMs). What rights does the library have, if any? The answer, in true lawyer fashion, depends on the rights granted in the license. If archiving and preservation are excluded, then libraries bear the entire burden, in theory and in practice, to sustain content that will need to be migrated to a new medium within a decade. Clifford Lynch articulated this sentiment well: "Forced obsolescence of content-the need to repurchase it over and over again for changing technologies, to hope that the content will be made available in the new format and that money can be found to acquire it again-is only one threat to the cultural and intellectual record."4 The business of technological controls and the legislative activity around those controls are on parallel courses, and no reprieve is in sight.

What about works in the public domain? One side of the argument is the cost could be less because copyright permissions are not incurred. On the other hand, publishers could increase the price because of value-added features-e.g., XML markup for full-text searching capabilities. Another possibility for high cost is the need for a source of income.

\section{LICENSES: INTERSECTION OF VALUES}

So, what happens during the convergence of the library, the publisher, and the law? The exchange of a print license tends to be initiated by the vendor. Since it already reflects the vendor's business model, it is up to the library to negotiate for the terms that meet the library's requirements. Librarians are entitled to strike and reword at will. It is becoming more common for libraries to add language to the license that addresses their local requirements, such as state mandated clauses, but more importantly, libraries can insert language that addresses fair use, ILL, reserves, coursepacks, MARC records or another patron discovery tool, and archival rights. 
There are a few rare times when an e-book business model will not require a license, and as long as a library is satisfied with their archival rights, avoiding a license is preferable. Generally, a license will be necessary, and there are some very good model licenses from the library community that can be used with e-book, as well as e-journal, licensing. An excellent example of a model license is the Council on Library and Information Resources/Digital Library Federation Model License <http:// library.yale.edu/ llicense/modlic.shtml $>$. While negotiating the license, it is the perfect time to let each party know what issues are important to them, even if it is not possible to include them in the license itself. The license will spell out how the subscription will be handled and should contain values that are important to each of the parties. Especially now, librarians need the license to have language that addresses the ability of the library to cancel or pare back subscriptions as necessary. Additionally, if e-books are bought with one-time money, then the license should cover archiving rights and the ability to find a mutually acceptable technology platform when it becomes necessary to migrate the content. Not all licensing language need be explicit; generalized language will sometimes be preferable to both parties, especially when speaking of the future. For example, licensing language can be used to further the interoperability of assistive technology with e-book formats or platforms, and one would want to mention the need for cooperation between systems and not specify software in the license.

The realm of fair use is, perhaps, the most polarizing force between libraries and publishers. Academic libraries, by virtue of their location, are both the beneficiaries and conduits of this privilege. As information providers, libraries' missions are about unfettered access for educational advancement. Publishers, in the other corner of the boxing ring, are determined to control and protect their intellectual property. In their world, "perfect protection would allow that all uses of a copyrighted work be accounted for: fair use and piracy would be virtually eliminated." 5 They fear unauthorized duplication and reproduction. Although DRMs are not innovative enough to distinguish patrons' legal and illegal uses, publishers could use this as an incentive to build features that limit how content is manipulated.

E-journal subscriptions are now including as a matter of course intellectual property rights such as interlibrary loan, library reserves, and coursepack rights. For example, with a one-e-book/one-user model, a library consortium will share a collection of e-books, which means each institution's user can view any of the available e-books, but a library cannot interlibrary loan one of the e-books to an institution outside of 
the consortium. When e-journals were first being licensed to libraries, they placed restrictions on library functions such as interlibrary loan and reserves. Now e-journal licenses routinely grant these traditional library rights, and e-book licenses should follow suit. Librarians want e-book publishers to either provide these functionalities now or plan for their future inclusion in their e-book business model.

When electronic books are purchased, libraries need to be assured that they are also buying archival rights. Since many of these titles are not being duplicated by print purchases, library values such as fair use, archival access, ILL, and library reserve rights must be addressed in an e-book license. Lucia Snowhill addresses the finer details between various disciplines, "The ability to manipulate an e-book collection easily to eliminate older editions is attractive where currency matters. In other disciplines where long-term research is essential, assurance of perpetual access will be vital."6

In terms of distribution models, libraries are accustomed to the mobility and ease of use of circulating print monographs. Is this possible with an electronic book? Again, the answer is it depends. Publishers have to be willing to market e-books in a manner that can be circulated like a print book; otherwise, a library's ability to rely on the doctrine of first sale is useless.

In the absence of specific clauses, language in the contract needs to cover the following issues: standards, technology access, authorized users, subscription models, withdrawn material, statistics, selection/ deselection, company solvency, archiving/preservation, continued access, and planned content obsolescence. Since the authors are not proffering legal advice, critical questions will be raised. This list is not comprehensive and not in an order of importance, but grouped more by logical relationships with each other.

Standards. Given the aforementioned infancy of the e-book business, is this possible? The following content standards are in the inceptive stages:

Open eBook Validator.

$<$ http://www.stg.brown.edu/service/oebvalid/>

This allows publishers to test whether or not a publication is compliant with the Open eBook Publication Structure Specification. Librarians can request that vendors utilize this measure. 
Open eBook Forum (OeBF).

$<$ http://www.openebook.org/about.htm>

The web site notes " $[\mathrm{OeBF}]$ is a trade and standards organization dedicated to the development and promotion of electronic publishing." In 2000, the American Library Association joined the OeBF, which lends the singular library presence to the process of developing standards. Critics point to their failure to address non-Roman character sets, and mathematical and scientific notation. Librarians can, at the very least, inquire if a vendor is a member.

Online Information Exchange (ONIX) for Books. $<$ http://www.editeur.org/>

ONIX is the international book industry's metadata standard for books and serials, and is maintained by EDItEUR, an international group of publishers managing the progress of the standards infrastructure for electronic commerce. Librarians can insist that vendors use the latest release. The caveat is the inclusion of a digital rights management system.

There are no standards, yet, for management-i.e., how content can be manipulated, distributed, and preserved. Librarians' partnerships with publishers and technology developers are critical in the development of standards. Taking a back seat will have serious social, cultural, and economic repercussions.

Archiving/Preservation. Libraries need to bargain for the right to a hard copy. Their relationships with publishers must include agreements for the safe, opportune, and dependable deposit of content, and to secure the rights necessary to archive the material. This demands a proactive approach; "libraries must take control of their own fate and get the actual printed book to ensure that e-books do not destroy libraries."7

Technology Access. Libraries are sensitive to patron access and the Americans with Disabilities Act, and are justifiably concerned with the limited audio capabilities of current e-books. On the other hand, publishers, taking their cues from the 2001 court case $A \&$ \& Records $v$. Napster, are worried about patrons stealing their content. On the legislative front, the Library of Congress addressed this problem. As reported in an October 28th article, their recent review of the Digital Millennium Copyright Act clarified one exception to circumventing protections, 
"e-books that do not allow disabled-access tools such as screen readers to function." 8

Authorized Users. The definition for authorized users for e-book licenses should be the same definition used within e-journal licenses. The interests of distance education students are assumed to be taken into account. Academic libraries are leaning toward the distribution model of networked e-books because of their distance education capabilities.

Statistics/Usage Monitoring/Privacy. Vendors currently track usage via Internet Protocol addresses; this practice should continue. If the e-books are not on a networked system, how will privacy be maintained? Will vendors be entitled to track user behavior without compromising privacy, or without making privacy an issue at all?

Subscription Model. Licenses need to clarify how monetary figures are calculated, but not necessarily the actual cost price. Do they charge a per book maintenance or access fee? The contract should also accurately reflect how the technology will work in practice.

Company Solvency. Harking back to e-book commerce as young, a clause should be included about contingency plans if a vendor goes out of business. Libraries learned this lesson from the serial agent Faxon, their filing bankruptcy, and the fallout. Clifford Lynch asked the important questions:

Do you have the right and the ability to reformat an e-book or a digital book in response to changes in standards or technologies or do you need to repurchase it? What happens when you upgrade or replace your e-book reader with another one? What happens when you replace the PC that might house your "library"? What happens if you replace one brand of e-book reader with another, perhaps because your reader vendor goes out of business? ${ }^{9}$

The license could say something to the effect-"Licensor will deliver any bought content in a tangible form to the Licensee if the Licensor becomes insolvent." This situation was imminent with netLibrary, which occurred in late 2001, until the Online Computer Library Center bought them.

Content. Does the contract address what will happen to withdrawn titles? Will an alternative format be provided? Will that format be one that can be migrated? What are the terms, and how will notification and "consent" occur? What about the continuation of access to material, if the vendor does go out of business? What are the penalties, if any, for canceling titles? Can titles be cancelled at all? 


\section{CONCLUSION-GOOD, BAD, AND UGLY}

The ugly truth is that libraries cannot afford to sustain more annual subscription fees. The distinguishing characteristics between academic e-journals and e-books are fading. They both have content that is updated online, they have editors and review processes, they have annual subscription fees, and libraries are making hard subscription choices. Generally, the limited funds in recurrent accounts are being spent on licensed e-journals, e-journals that have high impact factors and e-journals that may be part of consortial library packages gathered into shared title collections far larger than what one library could pay for. These licensed consortial library packages, sometimes referred to as the Big Deal, have taught libraries that ever increasing annual fee business models are not sustainable without the ability to contain costs. Lately e-journal subscriptions have risen $7-10 \%$ annually ${ }^{10}$ at a higher percentage than many library budgets. As noted by Van Orsdel, "More than 40 states report serious budget deficits. Endowed institutions are losing investment income, and library spending is being cut just about everywhere. Academic libraries face perhaps the most widespread budget losses in decades." 11 For example, Dennis Dillon, Associate Director for Research Services at The University of Texas at Austin, evaluates subscription e-book fees against the one-time cost for print books by calculating the e-book price for ten years. Even when an e-book business model is attractive, such as when a library gains unlimited user access to more research content on the Web than they would have with a print copy of a title, libraries are wary to begin another annual subscription cost. Libraries need the flexibility to choose the content that is important to their users in order to be fiscally responsible with their budgets.

Libraries are at odds, philosophically, with both publishers and the current legal framework. Libraries, as institutions, are the physical embodiment of the cultural and intellectual record. The conversion of the United States' literary heritage into e-book form is not going to be quick, cheap, occurring in leaps and bounds, nor methodical, and with the publishing industry holding all the copyright permission cards, so to speak, they can stack the deck as they please. Regarding the future, "Libraries, which make systematic, institutional investments in content on behalf of society as a whole, must be particularly vocal and articulate advocates of the need for preservation."12

There would be a bad future for e-book business models and licenses if the interested parties did not communicate with each other. This will not be the case because publishers recognize the benefits of communi- 
cation, "One advantage of entering the e-content business is that we publishers have much more contact with our customers and receive much more user feedback. Through this dialogue I am sure we will develop better e-content and enhanced services," 13 and librarians do too:

Those of us who occupy the existing links in the traditional chain of scholarly information need to find ways to transfer the inherent strengths, as well as the checks and balances of the traditional arrangement into the new environment. Ultimately it is to no one's advantage if the actions of libraries financially squeeze authors, publishers, and distributors; and it is not to the advantage of authors, publishers, and distributors to forgo the reliability and predictability of the library market for the uncertainties of selling scholarly materials directly to consumers. ${ }^{14}$

Concurrent with our business model and license discussions, the e-book industry is in a state of flux. A cursory view of any literature reveals the following words in many of the headlines: bankruptcy, mergers, and acquisitions. As long as fear, fear of illegal sharing of content and fear of no content to share, does not dictate the discussions, e-books will succeed in the library market.

The first e-books mirrored their print counterparts' content, and in some cases their graphical presentation. E-books have continued to evolve, such as The New Grove Dictionary of Music and Musicians into grovemusic.com, and so do their business models. It is a good time to be working with electronic content and intellectual property. Just as publishers and librarians have made great strides in constructing how e-journals will work in the library environment, the same foundation is being built for e-books right now.

\section{AN ALTERNATIVE: A DIGITAL LENDING RIGHT}

James Foley, taking his lead from the Europeans, suggests a Digital Lending Right (DLR). In his words, it is "a publicly-funded, collectively-administered, blanket licensing scheme for the noncommercial, private use of digital works." 15 The courts, passing judgment in the 1994 case American Geophysical Union v. Texaco Inc., suggested a licensing design that was supported by private resources and governed by a copyright collective. He analyzes the benefits from an economical 
perspective, noting that the more copyright transactions there are, the lower the price for each transaction. So, in the abstract sense, "a single, unified administration of a copyright collective would be the most economically efficient." 16 How does the library fit into this scheme? He explains it thus:

The Library of Congress could act as an independent arbiter of usage, while consolidating the accounting to one entity, or by contracting out facets of the administration to collectives that are then regulated. As with the [Public Lending Right] schemes, sampling could be used to estimate use in a fair and impartial way, open to public inspection. Libraries are uniquely situated to sample use. There would be no discrimination between major label (or any major publisher) and independent artists, as there would be no pecuniary incentive to do so. ${ }^{17}$

One possible obstacle to the backing of a DLR is the issue of assignability. Once a DLR plan was centralized and nationalized, it could attain reciprocity with foreign countries' authors and publishers. This could pave the way toward building a shared intellectual commons. In the words of Lawrence Lessig, "Our past had a commons that could not be designed away; that commons gave our culture great value. What value the commons of the future could bring us is something we are just beginning to see." 18

\section{NOTES}

1. Dillon, Dennis. "E-Books: The University of Texas Experience, Part I." Library Hi Tech 19, no. 2 (2001): 113.

2. Lynch, Clifford. "The Battle to Define the Future of the Book in the Digital World," First Monday 6, no. 6 (June 2001), <http://firstmonday.org/issues/issue6_ 6/lynch/index.html>, (accessed September 30, 2003).

3. Jacobs, Ian. "E-Books and Online Publishing: A Publisher's Perspective." The Charleston Advisor 4, no. 1 (July 2002): 60.

4. Lynch, Clifford. "The Battle to Define the Future of the Book in the Digital World," First Monday 6, no. 6 (June 2001), <http://firstmonday.org/issues/issue6_ 6/lynch/index.html>, (accessed September 30, 2003).

5. Foley, Joshua H. "Enter the Library: Creating a Digital Lending Right." Connecticut Journal of International Law 16, no. 369 (Spring 2001).

6. Snowhill, Lucia. "E-Books and Their Future in Academic Libraries." D-Lib Magazine 7, no. 7/8 (July/August 2001), <http://www.dlib.org/dlib/july01/snowhill/ 07snowhill.html>, (accessed September 29, 2003). 
7. Cohen, James. "Endangered Research: The Proliferation of E-Books and Their Potential Threat to the Fair Use Clause." Journal of Intellectual Property Law 9, no. 163 (Fall 2001).

8. Borland, John. "Feds Grant DMCA Exceptions." CNET News.com, (October 28, 2003): <http://news.com.com/2100-1028-5098639.html>, (accessed November 1, 2003).

9. Lynch, Clifford. "The Battle to Define the Future of the Book in the Digital World," First Monday 6, no. 6 (June 2001), <http://firstmonday.org/issues/issue6_6/ lynch/index.html>, (accessed September 30, 2003).

10. Van Orsdel, Lee; Born, Kathleen. "Big Chill on the Big Deal?" Library Journal 128, no. 7 (April 15, 2003): 56.

11. Ibid.

12. Lynch, Clifford. "The Battle to Define the Future of the Book in the Digital World," First Monday 6, no. 6 (June 2001), <http://firstmonday.org/issues/issue6_6/ lynch/index.html>, (accessed September 30, 2003).

13. Jacobs, Ian. "E-Books and Online Publishing: A Publisher's Perspective." The Charleston Advisor 4, no. 1 (July 2002): 60-61.

14. Dillon, Dennis. "Digital Books: Making Them Work for Publishers and Libraries." College and Research Libraries News 61, no. 5 (May 2000): 391-393.

15. Foley, Joshua H. "Enter the Library: Creating a Digital Lending Right." Connecticut Journal of International Law 16, no. 369 (Spring 2001).

16. Ibid.

17. Ibid.

18. Lessig, Lawrence. Code and Other Laws of Cyberspace. New York, New York: Basic Books, 1999, p. 141.

\section{REFERENCES}

Borland, John. "Feds Grant DMCA Exceptions." CNET News.com, (October 28, 2003): <http://news.com.com/2100-1028-5098639.html>, (accessed November 1, 2003).

Cohen, James. "Endangered Research: The Proliferation of E-Books and Their Potential Threat to the Fair Use Clause." Journal of Intellectual Property Law 9, no. 163 (Fall 2001).

Dillon, Dennis. "Digital Books: Making Them Work for Publishers and Libraries." College and Research Libraries News 61, no. 5 (May 2000): 391-393.

Dillon, Dennis. "E-Books: The University of Texas Experience, Part I." Library Hi Tech 19, no. 2 (2001): 113-124.

Foley, Joshua H. "Enter the Library: Creating a Digital Lending Right." Connecticut Journal of International Law 16, no. 369 (Spring 2001).

Jacobs, Ian. "E-Books and Online Publishing: A Publisher's Perspective." The Charleston Advisor 4, no. 1 (July 2002): 60-61.

Lessig, Lawrence. Code and Other Laws of Cyberspace. New York, New York: Basic Books, 1999. 
Lynch, Clifford. "The Battle to Define the Future of the Book in the Digital World," First Monday 6, no. 6 (June 2001), <http://firstmonday.org/issues/issue6_6/lynch/ index.html>, (accessed September 30, 2003).

Snowhill, Lucia. "E-Books and Their Future in Academic Libraries."D-Lib Magazine 7, no. 7/8 (July/August 2001), <http://www.dlib.org/dlib/july01/snowhill/07snowhill. html>, (accessed September 29, 2003).

Van Orsdel, Lee; Born, Kathleen. "Big Chill on the Big Deal?" Library Journal 128, no. 7 (April 15, 2003): 51-56. 